\title{
Different Ratios of Electron Beam Welding of Dissimilar Titanium Alloys: Ti-10V-2Fe-3Al and Ti-6Al-4V
}

\author{
Muhammad Iman Utama ${ }^{1}$, Janu Ageng Nugroho ${ }^{1}$, Abdul Aziz Ammar ${ }^{1}$, Nokeun Park ${ }^{1}$, and Eung Ryul Baek ${ }^{1^{*}}$ \\ ${ }^{1}$ School of Materials Science and Engineering, Yeungnam University, South Korea
}

\begin{abstract}
A welding of dissimilar alloy gives an optimum combination of high strength of Ti-10V-2Fe$3 \mathrm{Al}$ (Ti1023) and low cost of Ti-6Al-4V (Ti64). Three different fusion ratios of Ti1023 and Ti64 were resulting in a similar width size of the fusion zone (FZ) and heat affected zones (HAZ) whereas a thicker sample with the same fusion ratio generated a narrower size of FZ and HAZ. It resulted chemical composition in the FZ within a low $\beta$ phase stability than in Ti1023, which allowed the precipitation of high hardness $\alpha$ " martensitic in the as weld condition. In the HAZ of Ti1023, $\alpha_{\mathrm{s}}$ transformed into $\beta$ phase, which reduced the hardness and strength. Vickers hardness measurements confirmed the HAZ of Ti1023 was the softest area whereas the FZ was the hardest area. Consequently, in the as weld condition, the fracture occurred in the HAZ of TI1023 after the tensile test.
\end{abstract}

\section{Introduction}

The excellent mechanical ability, lightweight, and numerous corrosion resistance of titanium alloy develop a wide range application in industries [1]. Based on the different of beta $(\beta)$ phase stability in room temperature, titanium alloys are categorized into alpha $(\alpha)$, alpha-beta $(\alpha+\beta)$, and beta $(\beta)$ titanium. A common $\beta$ titanium alloy, Ti1023, develops a higher strength than $\alpha+\beta$ titanium alloys, which obtains $1200 \mathrm{MPa}$ of Ultimate Tensile Strength (UTS) subsequent to the heat treatment [2]. The $\beta$ stability of $\beta$ titanium alloys remain steady to take place single $\beta$ phase at ambient temperature, unlike $\alpha+\beta$ titanium. A precipitation of secondary alpha $\left(\alpha_{\mathrm{s}}\right)$ phase during aging treatment appears an increasing of strength in $\beta$ titanium alloy [3-4]. Meanwhile, Ti64 is one of the most common $\alpha+\beta$ titanium alloys which the UTS achieves $1000 \mathrm{MPa}$ and 15\% of elongation [5-6]. A low- cost and good proportion of strength-toughness allows favorable in the industrial application [7-8].

Welding is a process of generating metal structures by joining of materials through variety of processes. In common, a heating process is used to weld the metals which utilize open flames, laser beam, or electric arc [9]. There are several of problems which are able to occur like distortions and porosity [10]. Meanwhile, titanium alloys has good weld ability through wide variety welding processes. However, titanium alloys are easy to react in high temperature with oxygen and nitrogen that resulting from a decrement in the mechanical properties [11-12].

Recently, dissimilar welding of titanium alloys, which using Electron Beam Welding (EBW), expanded to achieve the exceptional quality of FZ and HAZ. EBW can accomplish an excellent quality of weld bead profile without occurring porosity [10]. A couple of studies about EBW dissimilar $\alpha+\beta / \alpha+\beta$ titanium alloys like Ti64 / Ti17 have resulted in a mechanical property of aswelded condition, which reached UTS of $960 \mathrm{MPa}$ with an elongation of $6 \%$, which the fracture occurred in the HAZ [13]. Nevertheless, investigation about EBW of dissimilar $\beta / \alpha+\beta$ titanium with different welding beam ratios has not performed yet. The aim of the present study was to define the correlation between phase transformation and mechanical property in EBW dissimilar titanium alloy of Ti1023 and Ti64 with different welding beam ratios.

\section{Materials and Methods}

The specimens that used in this study were Ti-10V-2Fe$3 \mathrm{Al}$ and Ti-6Al-4V (wt.\%). Rectangular samples within $1.5 \mathrm{~mm}$ thickness, $4 \mathrm{~mm}$ in width and $20 \mathrm{~mm}$ length. The EBW process condition shown in Table 1. The specimens welded in different welding ratios to reach the composition of 50:50, 34:66, and 66:34 of Ti64 and Ti1023, respectively. The welding beam arranged to be $0.18 \mathrm{~mm}$ offset either Ti64 or Ti1023 to reach the ratio of $34: 66$ and $66: 34$.

Table 1. Electron beam welding processing condition

\begin{tabular}{|c|c|c|c|c|c|c|}
\hline \multicolumn{7}{|c|}{ Welding Parameters } \\
\hline$\underset{\substack{\pi \\
\begin{subarray}{c} { \pi \\
\begin{subarray}{c}{0 \\
0{ \pi \\
\begin{subarray} { c } { 0 \\
0 } } \end{subarray}}\end{subarray}}{\stackrel{0}{0}}$ & 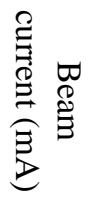 & 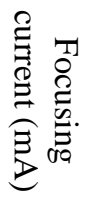 & 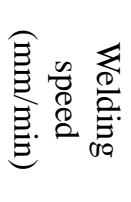 & 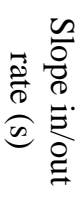 & 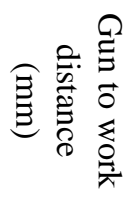 & 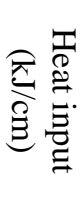 \\
\hline 150 & 40 & 1925 & 1200 & 0.5 & 70 & 300 \\
\hline
\end{tabular}

\subsection{Microstructure characterization}

The samples were mechanically polish with sand paper 2400 and diamond suspension from $6 \mu \mathrm{m}$ to $0.25 \mu \mathrm{m}$. The microstructure induced using a mixture of $10 \mathrm{~mL}$ $\mathrm{HF}, 5 \mathrm{~mL} \mathrm{HNO}_{3}$, and $85 \mathrm{~mL} \mathrm{H}_{2} \mathrm{O}$. Microstructure examination performed by Optical Microscopy (OM) 
and Secondary Electron Microscopy (SEM). The observation area of microstructure examination were Ti1023 base, Ti1023 HAZ, FZ, Ti64 base, and TI64

\subsection{Chemical composition observation}

The chemical composition of FZ obtained by using energy dispersive spectroscopy (EDS). The observed data were used to calculate the $\beta$ phase stability that formulated to $[\mathrm{Mo}]_{\mathrm{eq}}$ equation [14] as :

$$
\begin{aligned}
& {[\mathrm{Mo}]_{e q, w t}=1[\mathrm{Mo}]+2.9[\mathrm{Fe}]+1.7[\mathrm{Mn}]+1.7[\mathrm{Co}]+} \\
& 0.25[\mathrm{Cr}]+0.67[\mathrm{~V}]+0.2[\mathrm{Ta}]+0.28[\mathrm{Nb}]+0.4[\mathrm{~W}]- \\
& 1[\mathrm{Al}]
\end{aligned}
$$

\subsection{Mechanical testing}

The tensile test carried by Shimadzu AGS-100kNX. The tests strain rate were visually recorded, which the results analyzed using Digital Image Correlation (DIC) Vic-2D software. It performed to measure the exact strain in the strain-stress curve of the samples. The micro-vickers hardness conducted under an indentation load of $1000 \mathrm{gf}$ for $10 \mathrm{~s}$.

\section{Results and Discussions}
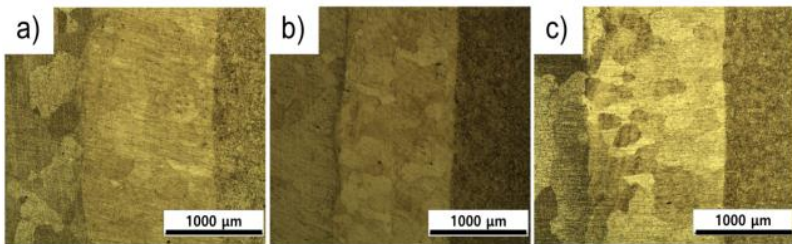

Fig. 1. Optical microscopy image of fusion zones of different welding ratios: (a) 50:50, (b) 34:66, (c) 66:34

Figure 1 showed the OM observation at a lower magnification presenting the full size of FZ of different welding ratios. These samples were relatively narrow. Figure 1a presented the OM observation of the sample of 50:50 welding ratio, which FZ size was $\sim 1.1 \mathrm{~mm}$. Figure $1 \mathrm{~b}$ and $1 \mathrm{c}$ showed the OM observation of samples of 34:66 and 66:34 welding ratio, respectively. That was a wider FZ at $66: 34$ for $\sim 1.2 \mathrm{~mm}$. Meanwhile, the FZ of 34:66 was $\sim 1 \mathrm{~mm}$. It was slightly lower than other sample's condition.
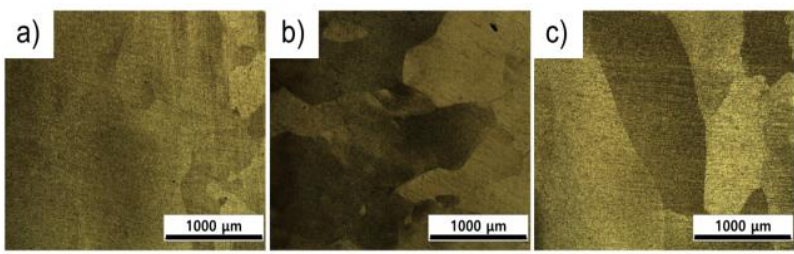

Fig. 2. Optical microscopy image of Ti1023 HAZ of different welding ratios: (a) 50:50, (b) 34:66, (c) 66:34

Figure 2 displayed the OM observation of Ti1023 HAZ of different welding ratios. It showed the sample 50:50 welding ratio at Ti1023 HAZ was $\sim 2.3 \mathrm{~mm}$ (as shown on Figure 2a). Meanwhile, Figure $2 b$ showed the OM observation of the sample of 34:66 welding ratio
HAZ. X-ray diffraction (XRD) observation of the zones conducted at $40 \mathrm{kV}$ and $30 \mathrm{~mA}$.

that the size was $\sim 2.2 \mathrm{~mm}$. Figure $2 \mathrm{c}$ presents the sample of 66.34 welding ratio that the size was $\sim 2.3 \mathrm{~mm}$. Based on OM measurement of HAZ, it was slightly narrower on ratio 34:66 than other conditions.
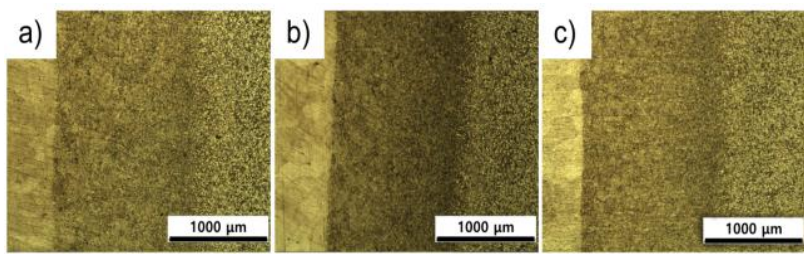

Fig. 3. Optical microscopy image of Ti64 HAZ of different welding ratios: (a) 50:50, (b) 34:66, (c) 66:34

However, Figure 3 showed the OM observation of Ti64 HAZ of different welding ratios. Figure $3 \mathrm{a}$ and $3 \mathrm{~b}$ present's samples of 50:50 and 34:66 welding ratios, respectively, which the width of both samples was $\sim 1.5 \mathrm{~mm}$. Figure $3 \mathrm{c}$ shows the sample of $66: 34$ welding ratio and the width was $\sim 1.6 \mathrm{~mm}$.

The different ratios in the welding processing were slightly affecting the width occurrence of the samples. A higher ratio of Ti1023 in the 34:66 sample was resulting in a slightly wider Ti1023 HAZ. As well as a greater ratio of Ti64 in the 66:34 sample was resulting in a lightly larger Ti64 HAZ

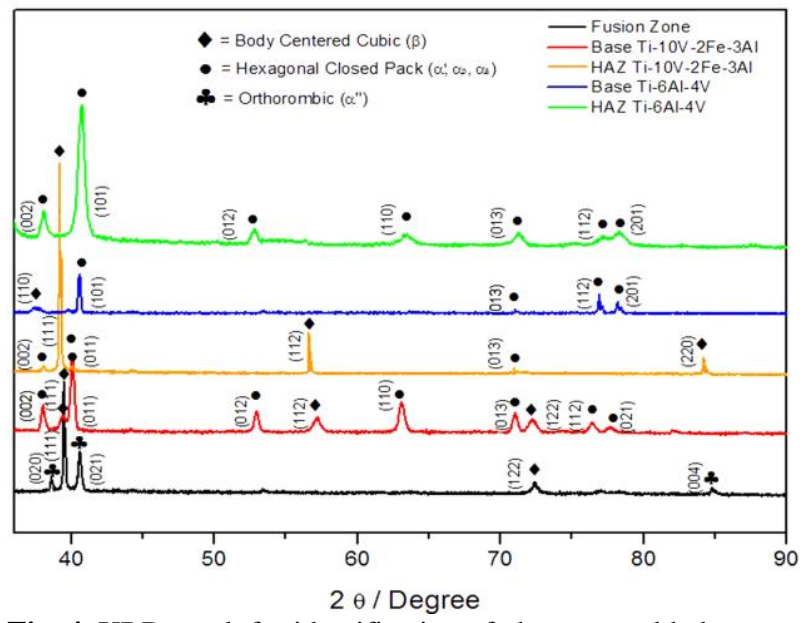

Fig. 4. XRD result for identification of phase as-welded.

Figure 4 displayed the XRD in FZ, Ti1023 base, Ti1023 HAZ, Ti64 base, and Ti64 HAZ. From that figure, $\alpha$ " martensitic obtained on FZ. Meanwhile, it did not achieve on other regions. Conversely, base and HAZ region obtained mostly $\mathrm{HCP}$ peak, which is $\alpha$ phase. Moreover, BCC peak also showed in the specimen, which means $\beta$ phase, remained after welding process. 
a)

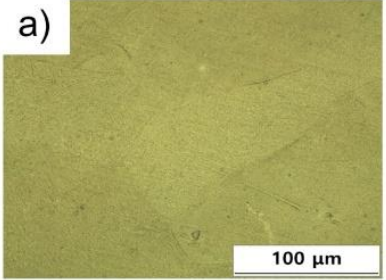

b)

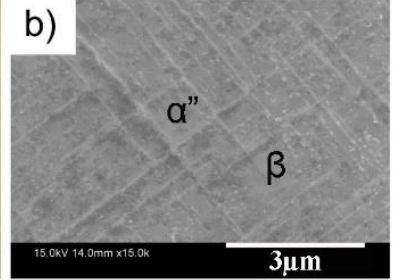

Fig. 5. Microstructure of fusion zone (FZ) at (a) lower magnification and (b) higher magnification

Figure 5a showed the optical microscopy observation in a higher magnification for FZ. That presented a clear microstructure and looks like a single $\beta$ phase. A higher magnification using SEM took in the same area shown in Fig. $5 b$ which resulted a precipitation of lamellar-looks like structure in all of samples. The X-ray diffraction pattern in Fig. 4 clarified that the lamellar structure was $\alpha$ " martensitic.

The unique chemical composition obtained in the FZ of as-welded sample in all samples. Table 2 observed all alloying element contents in the FZ. These were in between of the chemical contents in Ti1023 and Ti64, which also developed in the value of $[\mathrm{Mo}]_{\mathrm{eq}}($ Equation 1$)$. The low $\beta$ stability $\left([\mathrm{Mo}]_{\mathrm{eq}}<4 \%\right)$ contained in material induces an precipitation of $\alpha$ and $\alpha$ ' martensitic. Whereas, the high $\beta$ stability contained in the material accomplish better ability of $\beta$ phase to resist in the ambient temperature. Moreover, The material which accommodated reasonably high $\beta$ stability ([Mo $]_{\mathrm{eq}}$ $=4-9 \%$ ), admits precipitation of $\alpha$ " martensitic [15]. The present study result was in a good agreement with the previous study, which the $[\mathrm{Mo}]_{\mathrm{eq}}$ obtained FZ of $50: 50,66: 34$, and $34: 66$ were $8.14 \%, 7.47 \%$, and $7.5 \%$, respectively. Since, that allowed the precipitation of $\alpha$ " martensitic in the matrix of $\beta$ phase during cooling after the welding process.

Table 2. Chemical compositions of fusion zones of different welding ratios, Ti023 base and Ti64 base.

\begin{tabular}{|c|c|c|c|c|c|}
\hline Sample & Ti\% & V\% & Fe\% & Al\% & {$[$ Mo]eq } \\
\hline $\begin{array}{c}50: 50 \\
\text { FZ }\end{array}$ & 86.68 & 9.63 & 1.38 & 2.31 & 8.14 \\
\hline $\begin{array}{c}34: 66 \\
\text { FZ }\end{array}$ & 87.46 & 7.81 & 1.23 & 3.5 & 7.5 \\
\hline $\begin{array}{c}66: 43 \\
\text { FZ }\end{array}$ & 85.72 & 9.7 & 1.99 & 2.59 & 7.47 \\
\hline $\begin{array}{c}\text { Ti1023 } \\
\text { Base }\end{array}$ & 85 & 10 & 2 & 3 & 9.5 \\
\hline $\begin{array}{c}\text { Ti64 } \\
\text { Base }\end{array}$ & 90 & 4 & - & 6 & -3.3 \\
\hline
\end{tabular}

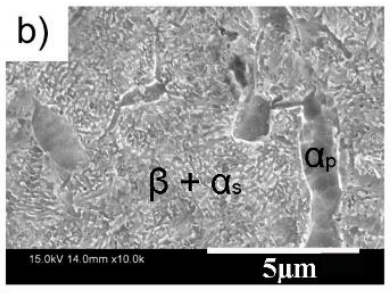

Fig. 6. Ti1023 base microstructure at (a) lower magnification and (b) higher magnification

Figure 6 displayed the OM observation of Ti1023 base in a higher magnification, which was a relatively homogeneous distribution of $\alpha_{p}$ in all of samples. Figure $6 \mathrm{~b}$ showed a SEM observation of Ti1023 base, which presented clearly the matrix of $\beta+\alpha_{s}$. Moreover, Figures $7 \mathrm{a}$ shows the microstructure of Ti1023 HAZ on optical microscope. The high magnification shown primary alpha still appeared in HAZ region (Figure 7b). it also shows the transformed $\beta$ phase which ensured by the XRD observation that shows the diminishing of alpha peak compare to Ti1023 base.
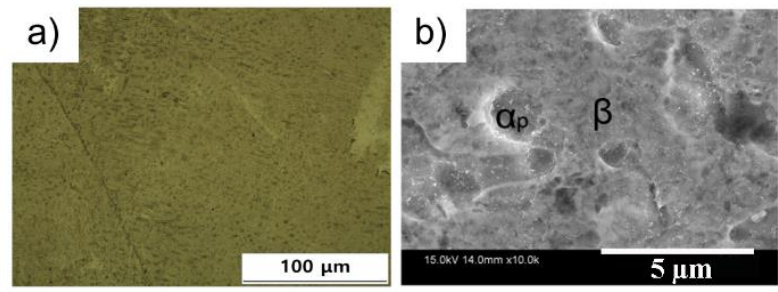

Fig. 7. HAZ microstructure of Ti1023 at (a) lower magnification and (b) higher magnification

Figure 8a-b indicated Ti64 base within globular $\alpha$ and lamellar $\alpha_{\mathrm{p}}$, which presented as the dark, whereas $\beta$ was the bright phase. Meanwhile, the HAZ of Ti64 showed $\alpha^{\prime}$ martensitic precipitation (Figure 9a-b). It confirmed on XRD result, which shows more of $\alpha$ peaks and the diminishing $\beta$ peak compared to that in the base which represents the transformation of some $\beta$ phase into the acicular $\alpha$ ' martensitic.
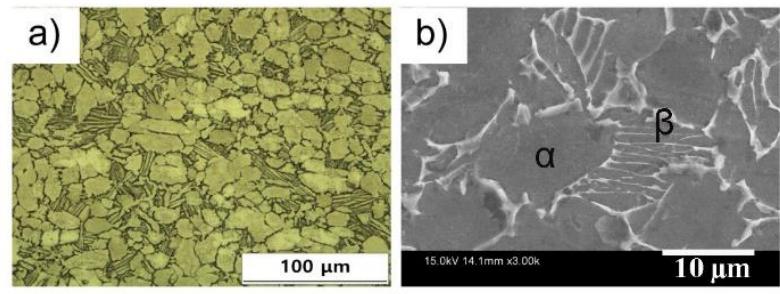

Fig. 8. Ti64 base microstructure at (a) lower magnification and (b) higher magnification. 


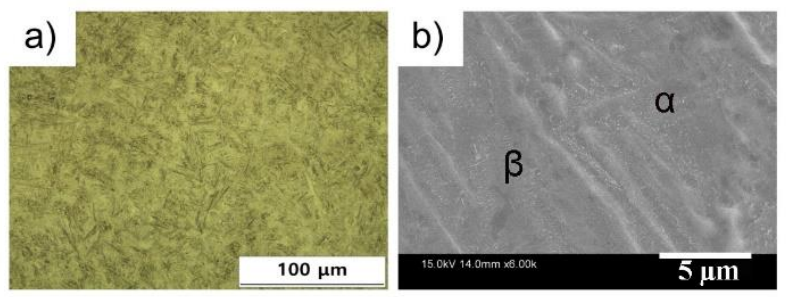

Fig. 9. HAZ of Ti64 microstructure at (a) lower magnification and (b) higher magnification

Hardness value of the various welding ratios shows the 50:50 has a high [Mo] $]_{\text {eq }}$ number, which was low precipitation $\alpha$ ' and $\alpha$ " in the microstructure of FZ (Figure 10). In the HAZ of TI1023, $\alpha_{\mathrm{s}}$ transformed into $\beta$ phase, which reduced the hardness and strength of the area. Vickers hardness measurements confirmed the HAZ of Ti1023 was the softest area whereas the FZ was the hardest area. Tensile test showed the highest was 50:50 ratio (UTS $969 \mathrm{MPa}$ and $6.9 \%$ Elongation). It correlated with $[\mathrm{Mo}]_{\mathrm{eq}}$ and hardness value. It obtained the higher UTS than the other ratios that shown on Figure 11, as a main factor to increasing the value was the precipitation of $\alpha$ '. The fracture happened at Ti1023 HAZ area for all welding ratios.

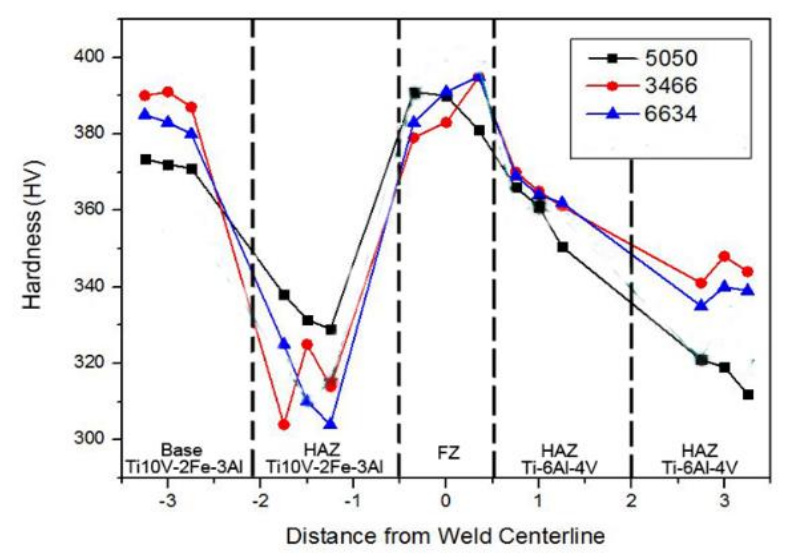

Fig. 10. Hardness results of all sample condition

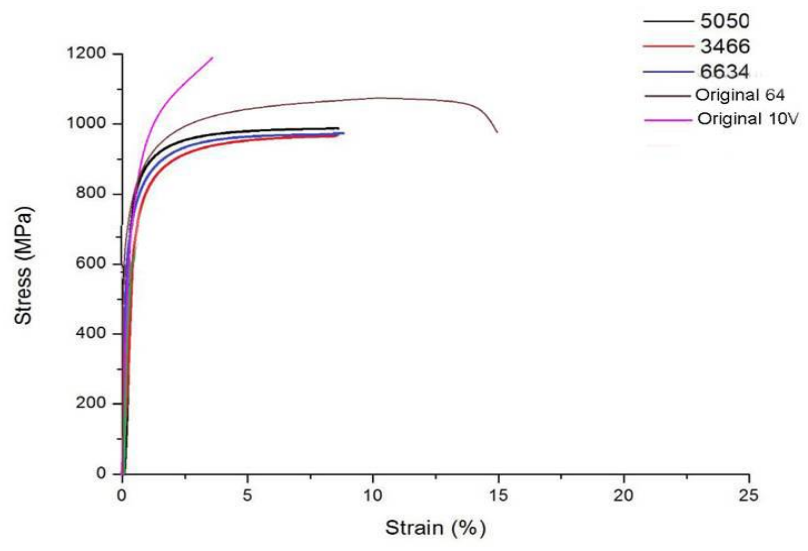

Fig. 11. Engineering stress-strain curve of all sample condition.

\section{Conclusions}

The result of EBW dissimilar titanium alloy of Ti1023 and Ti64 with different welding ratios already investigated. The current work presented the mechanical properties of 50:50, 34:66, and 66:34 ratios were in similar values. We discussed the phase transformation in the Ti1023 and Ti64 base, HAZ and FZ as well as the relationship to the mechanical properties. The details are as follows:

1. $\alpha_{\mathrm{s}}$ transformed into $\beta$ phase during the welding, which resulting low hardness value on Ti1023 HAZ. It confirmed on tensile test value, which the fracture occurred since the weak region of HAZ.

2. $\alpha$ ' acicular structure obtained in Ti64 HAZ and enhanced the hardness value of the material.

3. FZ zone achieved new chemical composition, which had moderately high $\beta$ stability. It allows the precipitation of acicular $\alpha$ " martensitic in the matrix of $\beta$ phase after the welding. Moreover, acicular $\alpha$ " martensitic generated a high hardness value. Meanwhile, ratio 50:50 had the best result compare to $34: 64,66: 43$ of Ti64 and Ti1023, respectivel.

This study supported by Ministry of Trade Industry \& Energy (MOTIE) Republic of Korea.

\section{References}

1 J.D. Beal, R. Boyer, D. Sanders, T.B. Company, Forming of Titanium and Titanium Alloys, 14 (2006) 656-669. doi:10.1361/asmhba0005146.

2 D. Luquiau, X. Feaugas, M. Clavel, Cyclic softening of the Ti-10V-2Fe-3A1 titanium alloy, 224 (1997) 146-156.

3 J.W. Lu, Y.Q. Zhao, P. Ge, H.Z. Niu, Y.S. Zhang, W. Zhang, P.X. Zhang, Materials Science \& Engineering A Microstructure and mechanical properties of new high strength beta-titanium alloy Ti-1300, $621 \quad$ (2015) 182-189. doi:10.1016/j.msea.2014.10.072.

4 J. Fan, J. Li, H. Kou, K. Hua, B. Tang, Y. Zhang, Influence of solution treatment on microstructure and mechanical properties of a near $\beta$ titanium alloy Ti-7333, Mater. Des. 83 (2015) 499-507. doi:10.1016/j.matdes.2015.06.015.

5 H. Matsumoto, H. Yoneda, K. Sato, S. Kurosu, E. Maire, D. Fabregue, T.J. Konno, A. Chiba, Roomtemperature ductility of $\mathrm{Ti}-6 \mathrm{Al}-4 \mathrm{~V}$ alloy with $\alpha$ ' martensite microstructure, Mater. Sci. Eng. A. 528(2011)1512-1520.

doi:10.1016/j.msea.2010.10.070.

6 G.C. Obasi, S. Birosca, J.Q. Fonseca, M. Preuss, Effect of $b$ grain growth on variant selection and texture memory effect during $a$ ! b! a phase transformation in $\mathrm{Ti}-6 \mathrm{Al}-4 \mathrm{~V}$, Acta Mater. 60 (2012)1048-1058. 
doi:10.1016/j.actamat.2011.10.038.

7 K. Gu, H. Zhang, B. Zhao, J. Wang, Y. Zhou, Z. Li, Effect of cryogenic treatment and aging treatment on the tensile properties and microstructure of $\mathrm{Ti}$ 6Al-4V alloy, Mater. Sci. Eng.A.584(2013)170176. doi:10.1016/j.msea.2013.07.021.

8 M. Villa, Metallurgical and Mechanical Modelling of Ti-6Al-4V for Welding, (2016).

9 C. Leyens, M. Peters, Titanium and titanium alloys, 2003

10 Y.M. Ahmed, K. Salleh, M. Sahari, M. Ishak, Welding of Titanium ( Ti-6Al-4V ) Alloys: A Review Welding of Titanium ( Ti-6Al-4V ) Alloys : A Review, (2012).

11 M.J. Donachie, Titanium - A Techinacal Guide, 2000. doi:10.5772/1844.

12 G. Lutjering, J.C. Williams, Titanium, 2nd Editio, Springer Berlin, Heidelberg, 2007.

13 V.E. Yeganeh, P. Li, Effect of beam offset on microstructure and mechanical properties of dissimilar electron beam welded high temperature titanium alloys, Mater. Des. 124 (2017) 78-86. doi:10.1016/j.matdes.2017.03.056.
14 J.D. Cotton, R.D. Briggs, R.R. Boyer, S Tamirisakandala, P. Russo, N. Shchetnikov, J.C. Fanning, State of the Art in Beta Titanium Alloys for Airframe Applications, 67 (2015) 1281-1303. doi:10.1007/s11837-015-1442-4.

15 A. Bhattacharjee, Effect of b grain size on stress induced martensitic transformation in $b$ solution treated $\mathrm{Ti}-10 \mathrm{~V}-2 \mathrm{Fe}-3 \mathrm{Al}$ alloy, 53 (2005) 195200. doi:10.1016/j.scriptamat.2005.03.039. 